\title{
Establishing a prognostic threshold for total copy number variation within adult IDH- mutant grade II/III astrocytomas
}

\author{
Kanish Mirchia', Matija Snuderl ${ }^{2}$, Kristyn Galbraith ${ }^{1}$, Kimmo J. Hatanpaa ${ }^{3}$, Jamie M. Walker ${ }^{4,5}$ and \\ Timothy E. Richardson ${ }^{1 *}$
}

Keywords: Copy number variation, CNV, Copy number alterations, CNA, IDH mutation, Astrocytoma, Glioma, Glioblastoma, GBM, TCGA

Prior to the $2016 \mathrm{WHO}$ update, adult astrocytomas were graded exclusively by histologic features, where grade III anaplastic astrocytomas were separated from grade II diffuse infiltrating astrocytomas on the basis of mitotic figures, and glioblastomas (GBM; grade IV) were defined based on the presence of microvascular proliferation and/or tumor necrosis [9]. With the establishment of the 2016 WHO Classification of Tumours of the Central Nervous System guidelines, adult astrocytomas have been segregated into $I D H$-wildtype and $I D H$-mutant groups due to the significant prognostic advantage conferred by the presence of an $I D H 1$ or $I D H 2$ mutation $[9,14]$. Since this update, much work has been done to establish additional prognostic factors in both $I D H$-wildtype and $I D H$-mutant astrocytomas to further subclassify these groups and to aid in the understanding of the underlying biology $[1-3,5]$.

We have previously investigated the influence of total copy number variation (CNV) on clinical outcome in adult astrocytomas in a variety of cohorts, including cases from The Cancer Genome Atlas (TCGA) dataset [10-13]. In $I D H$-mutant lower-grade gliomas (grades II and III), elevated total CNV (16-22\%) is associated with poor clinical outcome (defined in these earlier reports as rapid progression to GBM and patient survival intervals $<24$ months) compared to histologically similar tumors with lower total $\mathrm{CNV}(8-10 \%)$, and the level of total genomic $\mathrm{CNV}$ is inversely correlated with both progression-free and overall survival in linear regression models. Total CNV appears to

\footnotetext{
* Correspondence: RichaTim@Upstate.edu

${ }^{1}$ Department of Pathology, State University of New York, Upstate Medical University, Syracuse, NY 13210, USA

Full list of author information is available at the end of the article
}

have no prognostic value in $I D H$-wildtype astrocytoma or $I D H$-mutant GBM groups [10-12].

Unlike other prognostic factors, however, $\mathrm{CNV}$ is more difficult to utilize clinically, as it is not a simple "present-or-absent" model like IDH1/2 mutations. To address this, we used the cBioPortal interface $[4,7]$ to reanalyze the survival and $\mathrm{CNV}$ data from $\mathrm{IDH}$-mutant grade II/III astrocytomas in our previous publications $(n=67)[10,12]$ to establish a simple and reasonable threshold that could be used to reliably predict clinical outcomes within the $I D H$-mutant, 1p/19q-retained lower-grade astrocytoma subgroup. We defined CNV as the percentage of the genome with alterations meeting the criteria of $\log 2>0.3$; copy number data was derived from Affymetrix SNP6 (Santa Clara, CA, USA) and Agilent $224 \mathrm{~K} / 415 \mathrm{~K}$ (Santa Clara, CA, USA) platforms [1]. Preliminary data from our previous studies suggested potential clinically useful CNV cutoff levels of 10,15 , and $18 \%[10,12]$.

Using Kaplan-Meier analysis on cases from our previous publications and additional cases from the TCGA database (total $n=194 I D H$-mutant lower-grade astrocytomas), we evaluated each of these potential thresholds. There was a significant survival difference between cases at each threshold evaluated: $10 \%(<10 \% \mathrm{CNV}, 105.2$ month median survival; $>10 \% \mathrm{CNV}, 62.2$ month median survival; $p=0.0020$ ) (Fig. 1a), 15\% (<15\% CNV, 105.2 month median survival; $>15 \% \mathrm{CNV}, 50.1$ month median survival; $p<0.0001)$ (Fig. 1b), and $18 \%(<18 \% \mathrm{CNV}$, 98.2 month median survival; >18\% CNV, 41.2 month median survival; $p=0.0003$ ) (Fig. 1c). There was no significant patient survival difference in the $10 \%$ vs $15 \%$ $\mathrm{CNV}$ thresholds, and an additional group with $\mathrm{CNV}$ 
A

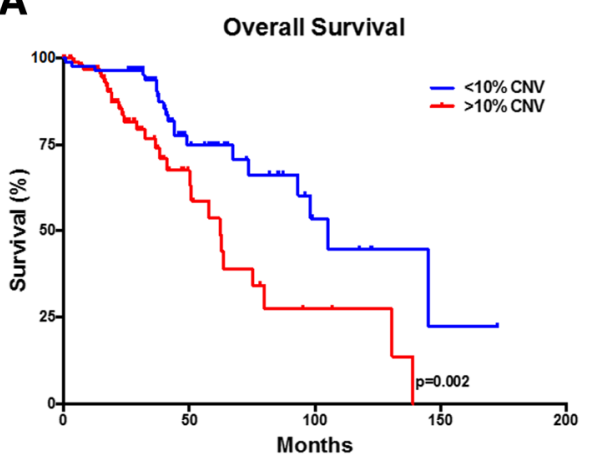

B

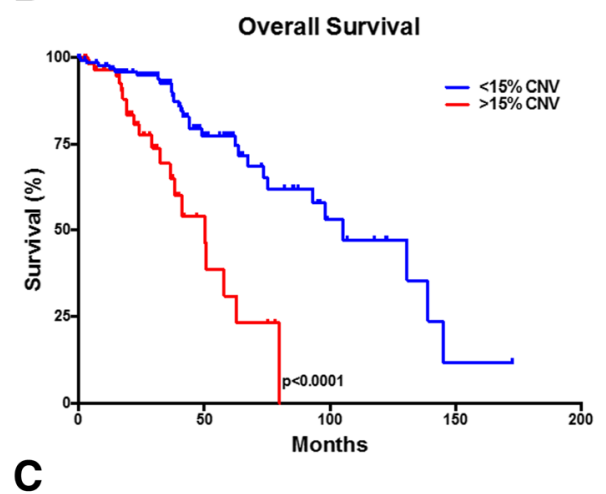

C

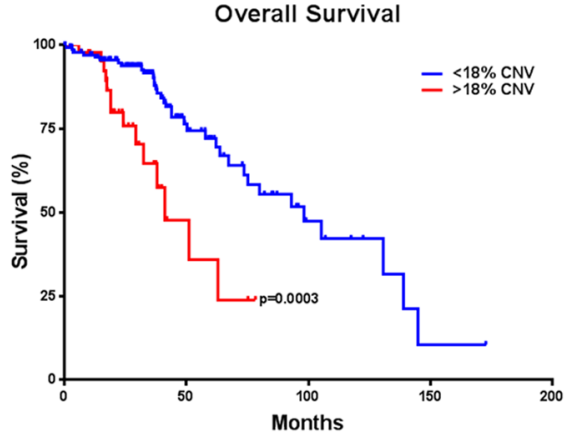

D

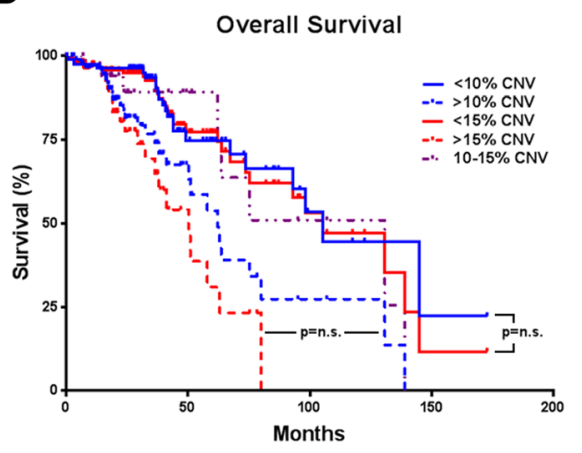

E

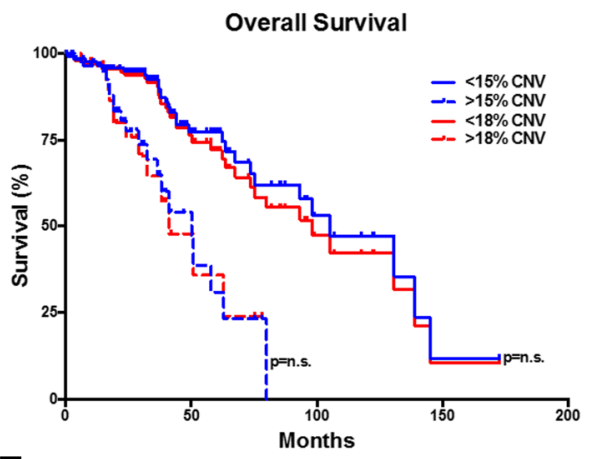

F

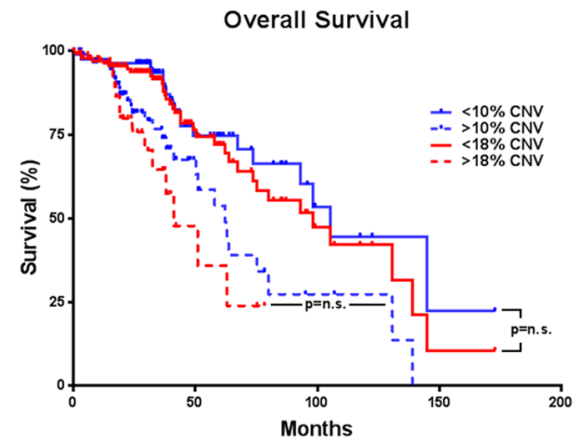

Fig. 1 Kaplan-Meier survival curves demonstrating survival differences using 10\% overall CNV as a threshold for poor clinical outcome ( $p=0.0020)$ (a), using 15\% overall CNV as a threshold for poor clinical outcome $(p<0.0001)(\mathbf{b})$, and using 18\% overall as a threshold for poor clinical outcome ( $p=0.0003)$ (c). Kaplan-Meier survival curves demonstrating no significant difference between 10 and 15\% CNV thresholds (additionally, $<10 \%$ vs $10-15 \% p=0.6003 ; 10-15 \%$ vs $>15 \% p=0.0113)$ (d), no significant difference between 15 and $18 \%$ CNV thresholds $(<15 \%$ vs $<18, p=$ $0.5949 ;>15 \%$ vs $>18 \% p=0.9015)(\mathbf{e})$, and no significant difference between 10 and $18 \%$ CNV thresholds $(<10 \%$ vs $<18, p=0.4791 ;>10 \%$ vs $>$ $18 \% p=0.2672)(\mathbf{f})$. Copy number variation is expressed as a percentage of the total genome, $\log 2>0.3$ as reported previously [10, 12]

between 10 and $15 \%$ (130.8 month median survival) was not significantly different than the group with $<10 \%$ $\operatorname{CNV}(p=0.6003)$, however these cases had significantly better clinical outcomes than cases with $>15 \% \mathrm{CNV}$ ( $p=0.0113$ ) (Fig. 1d), suggesting $15 \%$ as the better cutoff point. No significant difference was found between the 15 and 18\% thresholds (Fig. 1e) or the 10 and $18 \%$ thresholds (Fig. 1f), however the 18\% threshold would exclude $>50 \%$ of cases from one of our previously reported poorly performing cohorts [12]. The 15\% CNV threshold had a sensitivity of $85 \%$, specificity of $90 \%$, positive predictive value (PPV) of $77 \%$, and negative predictive value (NPV) of $94 \%$. The $10 \%$ CNV threshold had a relatively low specificity (57\%) and PPV (32\%) and the $18 \% \mathrm{CNV}$ threshold had a lower sensitivity (75\%) (Table 1). Based on these models, we suggest that a judicious CNV cutoff for predicting poor clinical outcome in adult $I D H$-mutant lower-grade astrocytomas would be around $15 \%$. It is important to note that these results are from a single, albeit relatively large, data source and as such should be validated prospectively. It would be of interest to evaluate our suggested cutoff using other 
Table 1 Comparison of 10,15, and 18\% CNV thresholds

\begin{tabular}{lllll}
\hline CNV Level & Sensitivity & Specificity & PPV & NPV \\
\hline $10 \%$ & $88 \%$ & $57 \%$ & $32 \%$ & $96 \%$ \\
$15 \%$ & $85 \%$ & $90 \%$ & $77 \%$ & $94 \%$ \\
$18 \%$ & $75 \%$ & $93 \%$ & $75 \%$ & $93 \%$ \\
\hline
\end{tabular}

large-scale cohorts to confirm our recommendation of $15 \% \mathrm{CNV}$ or alternatively help improve the robustness of our model and refine this threshold.

While total CNV is not currently a regularly measured factor at the time of diagnosis, recent proof-of-concept studies have shown that genetic and epigenetic variables such as CNV and various mutations, individual gene amplifications/deletions, and chromosomal gains/losses can be identified rapidly $[6,8]$, and thus CNV estimates may soon be available within days of histologic diagnosis, raising the possibility for its use as an additional clinical factor guiding prognosis in $I D H$-mutant lower-grade astrocytomas.

\section{Acknowledgements}

The authors would like to thank Dr. Michel Nasr, Elizabeth Rosaschi, and the Department of Pathology at SUNY Upstate Medical University for publication costs.

\section{Authors' contributions}

Conception of the work: KM, MS, TER; Design of the work: KM, MS, KG, KJH, JMW, TER.; Acquisition/analysis/interpretation of the data: KM, MS, KG, KJH, JMW, TER; Creation of new software used in the work: not applicable; Drafted the work or substantively revised it: KM, JMW, TER All authors read and approved the final manuscript.

\section{Funding}

M.S. is supported in part by a Friedberg Charitable Foundation.

\section{Availability of data and materials}

The full dataset used in this study is freely available at www.cbioportal.org and https://www.cancer.gov/about-nci/organization/ccg/research/structuralgenomics/tcga.

Ethics approval and consent to participate

Not applicable.

\section{Consent for publication}

Not applicable.

\section{Competing interests}

The authors declare that they have no competing interests.

\section{Author details}

'Department of Pathology, State University of New York, Upstate Medical University, Syracuse, NY 13210, USA. ²Department of Pathology, New York University Langone Health, New York City, NY 10016, USA. ${ }^{3}$ Department of Pathology, University of Texas Southwestern Medical Center, Dallas, TX 75390, USA. ${ }^{4}$ Department of Pathology, University of Texas Health Science Center, San Antonio, TX 78229, USA. ${ }^{5}$ Glenn Biggs Institute for Alzheimer's \& Neurodegenerative Diseases, University of Texas Health Science Center, San Antonio, TX 78229, USA.
Received: 1 July 2019 Accepted: 22 July 2019

Published online: 26 July 2019

\section{References}

1. Brennan CW, Verhaak RG, McKenna A, Campos B, Noushmehr H, Salama SR, Zheng S, Chakravarty D, Sanborn JZ, Berman SH et al (2013) The somatic genomic landscape of glioblastoma. Cell 155:462-477. https://doi.org/10.1 016/j.cell.2013.09.034

2. Cancer Genome Atlas Research N, Brat DJ, Verhaak RG, Aldape KD, Yung WK, Salama SR, Cooper LA, Rheinbay E, Miller CR, Vitucci M et al (2015) Comprehensive, integrative genomic analysis of diffuse lower-grade gliomas. N Engl J Med 372:2481-2498. https://doi.org/10.1056/NEJMoa1402121

3. Ceccarelli M, Barthel FP, Malta TM, Sabedot TS, Salama SR, Murray BA, Morozova O, Newton Y, Radenbaugh A, Pagnotta SM et al (2016) Molecular profiling reveals biologically discrete subsets and pathways of progression in diffuse glioma. Cell 164:550-563. https://doi.org/10.1016/j.cell.2015.12.028

4. Cerami E, Gao J, Dogrusoz U, Gross BE, Sumer SO, Aksoy BA, Jacobsen A, Byrne CJ, Heuer ML, Larsson E et al (2012) The cBio cancer genomics portal: an open platform for exploring multidimensional cancer genomics data. Cancer Discov 2:401-404. https://doi.org/10.1158/2159-8290.CD-12-0095

5. Cimino PJ, Zager M, McFerrin L, Wirsching HG, Bolouri $H$, Hentschel B, von Deimling A, Jones D, Reifenberger G, Weller M et al (2017) Multidimensional scaling of diffuse gliomas: application to the 2016 World Health Organization classification system with prognostically relevant molecular subtype discovery. Acta Neuropathol Commun 5:39. https:/doi.org/10.1186/ s40478-017-0443-7

6. Euskirchen P, Bielle F, Labreche K, Kloosterman WP, Rosenberg S, Daniau M, Schmitt C, Masliah-Planchon J, Bourdeaut F, Dehais C et al (2017) Same-day genomic and epigenomic diagnosis of brain tumors using real-time nanopore sequencing. Acta Neuropathol 134:691-703. https://doi.org/10.1 007/s00401-017-1743-5

7. Gao J, Aksoy BA, Dogrusoz U, Dresdner G, Gross B, Sumer SO, Sun Y, Jacobsen A, Sinha R, Larsson E et al (2013) Integrative analysis of complex cancer genomics and clinical profiles using the cBioPortal. Sci Signal 6:pl1. https://doi.org/10.1126/scisignal.2004088

8. Hench J, Bihl M, Bratic Hench I, Hoffmann P, Tolnay M, Bosch Al Jadooa N, Mariani L, Capper D, Frank S (2018) Satisfying your neuro-oncologist: a fast approach to routine molecular glioma diagnostics. Neuro-Oncology 20: 1682-1683. https://doi.org/10.1093/neuonc/noy128

9. Louis DN, Perry A, Reifenberger G, von Deimling A, Figarella-Branger D, Cavenee WK, Ohgaki H, Wiestler OD, Kleihues P, Ellison DW (2016) The 2016 World Health Organization classification of tumors of the central nervous system: a summary. Acta Neuropathol 131:803-820. https://doi.org/10.1007/ s00401-016-1545-1

10. Mirchia K, Sathe AA, Walker JM, Fudym Y, Galbraith K, Viapiano MS, Corona RJ, Snuderl M, Xing C, Hatanpaa KJ et al (2019) Total copy number variation as a prognostic factor in adult astrocytoma subtypes. Acta Neuropathol Commun 7:92. https://doi.org/10.1186/s40478-019-0746-y

11. Richardson TE, Patel S, Serrano J, Sathe AA, Daoud EV, Oliver D, Maher EA, Madrigales A, Mickey BE, Taxter T et al (2019) Genome-wide analysis of glioblastoma patients with unexpectedly long survival. J Neuropathol Exp Neurol 78:501-507. https://doi.org/10.1093/jnen/nlz025

12. Richardson TE, Sathe AA, Kanchwala M, Jia G, Habib AA, Xiao G, Snuderl M, Xing C, Hatanpaa KJ (2018) Genetic and epigenetic features of rapidly progressing IDH-mutant Astrocytomas. J Neuropathol Exp Neurol 77:542548. https://doi.org/10.1093/jnen/nly026

13. Richardson TE, Snuderl M, Serrano J, Karajannis MA, Heguy A, Oliver D, Raisanen JM, Maher EA, Pan E, Barnett S et al (2017) Rapid progression to glioblastoma in a subset of IDH-mutated astrocytomas: a genome-wide analysis. J Neuro-Oncol 133:183-192. https://doi.org/10.1007/s11060-017-2431-y

14. Yan H, Parsons DW, Jin G, McLendon R, Rasheed BA, Yuan W, Kos I, BatinicHaberle I, Jones S, Riggins GJ et al (2009) IDH1 and IDH2 mutations in gliomas. N Engl J Med 360:765-773. https://doi.org/10.1056/NEJMoa0808710

\section{Publisher's Note}

Springer Nature remains neutral with regard to jurisdictional claims in published maps and institutional affiliations. 